\title{
CULTURA PELA PALAVRA: COLETÂNEA DE ENSAIOS, ENTREVISTAS E DISCURSOS DOS MINISTROS DA CULTURA 2003 - 2010/GILBERTO GIL E JUCA FERREIRA
}

\author{
Eduardo Harder ${ }^{1}$
}

O escritor Lima Barreto, um intelectual conhecido pelo uso da ironia em seus escritos, publicou uma crônica em 1922 intitulada Iaiá das Marimbas. Logo no início do texto ele se apresenta ao leitor como um "um observador de costumes, relacionandoos com a formação da nacionalidade". A seguir revela a prisão de "quase uma centena de frequentadores e frequentadoras de candomblés" pela "polícia formidável do Senhor Geminiano". O autor interpreta essa ação policial que "prendeu tanta gente, sem culpa nem crime formado" a partir da "estratificação de nossa sociedade".

O narrador aproxima a sua própria biografia com os fatos e afirma: "Eu mesmo, apesar de todas as intoxicações, inclusive a científica, tenho a tentação dos 'candomblés', 'canjerês', 'mambembes' e os frequento”. E arremata com bom humor ao lançar uma provocação: "Com a polícia acontece o mesmo. Eles gostam de tais cerimônias religiosas de certa maneira, tanto assim que dão um tento para surpreendêlas" (Lima Barreto, 2004: 525).

A perspectiva literária lançada por autores como Lima Barreto permite um registro da memória social de um passado pouco distante e, principalmente, revela elementos para a compreensão de uma dialética local renitente. Tal dinâmica conjuga uma proposta de matriz conservadora voltada à manutenção da ordem vigente e o discurso de afirmação de um imaginário coletivo fundado no ideal de integração nacional que apague ou ao menos mitigue o reconhecimento da diversidade cultural, linguística, identitária, étnica, de cosmovisões, saberes, conhecimentos, etc.

Ao lembrar das "sombras do ser murado" e da "alma exilada" em escritores e intelectuais como Lima Barreto, Alfredo Bosi rememora em Dialética da colonização seu conhecido ensaio Cultura brasileira e Culturas brasileiras, escrito originalmente entre 1979 e 1980. No posfácio Olhar em retrospecto, o autor observa que essa dialética da colonização que confere título à obra "não é tanto a gangorra de nacionalismo e cosmopolitismo" mas, em outro sentido, "uma "luta entre modos de pensar localistas,

\footnotetext{
${ }^{1}$ Universidade Federal do Paraná, Brasil.
} 
espelho dos cálculos do aqui-e-agora, e projetos que visam à transformação da sociedade recorrendo a discursos originados em outros contextos, mas forrados de argumentos universais".

A perplexidade "que o curso dos anos só tem feito crescer" sobre o "caráter plural das culturas" enseja no último parágrafo do livro, um "tênue lume de esperança" de que uma "dialética da civilização" possa gerar "esparsos pensamentos, palavras e atos de uma cultura de resistência ainda não vencida pelas forças da desintegração" colonizadora (Bosi, 1992: 382-383).

No ano de 2003, Alfredo Bosi concedeu entrevista a um semanário de circulação nacional para discorrer sobre crítica cultural e a conjuntura política. Instigado a tecer comentários sobre as expectativas com a gestão do recém nomeado Ministro da Cultura Gilberto Gil, a resposta expressou um sentimento comum entre as pessoas naquele momento, ao afirmar que tudo estava muito no início, no entanto não conseguia “enxergar um projeto claro na área cultural. A escolha de Gilberto Gil como ministro foi uma surpresa. Por enquanto, Gil continua sendo um grande criador de ritmos, um talento." Por fim, ele acrescenta um indicador importante para a futura avaliação da gestão: "Sua contribuição para a música é inegável. Resta esperar que ele contribua para o bem comum" (Bosi, 2003).

Após o término das gestões de Gilberto Gil e de seu sucessor Juca Ferreira no Ministério da Cultura brasileiro entre 2003 e 2010, Alfredo Bosi publicou um curto ensaio com o título de Interação virtuosa, em que apresenta a sugestão de ampliação do "projeto dos Pontos de Cultura já instituídos pelo Ministério da Cultura na gestão de Gilberto Gil" e ressalta o caráter intersetorial conferido às políticas culturais em interface com a educação, trabalho, meio ambiente e relações internacionais.

O cerne do ensaio versa sobre a busca do bem comum, o qual poderia advir de uma "interação virtuosa de liberdade e responsabilidade". O Ministério da Cultura teria o "dever de equilibrar duas tendências aparentemente opostas". E quais seriam essas tendências? De um lado, a "salutar isenção política em face da diversidade das manifestações culturais, que devem guardar independência na medida em que emergem da sociedade civill". Por outro, o equilíbrio almejado dependeria também da "capacidade de apoiar efetivamente a difusão dos bens materiais e espirituais na medida em que o Estado é responsável pela sua democratização no interior dessa mesma sociedade" (Bosi, 2010). 
O esforço em encontrar o ponto de equilíbrio entre liberdade e responsabilidade na formulação e execução de políticas públicas no campo da cultura, em um país cuja crônica literária revela o longo caminho a ser percorrido para o efetivo reconhecimento da diversidade e da pluralidade de sua sociedade, constitui a linha argumentativa central da obra Cultura pela palavra: coletânea de artigos, discursos e entrevistas dos ministros da Cultura 2003-2010/Gilberto Gil \& Juca Ferreira. A publicação foi lançada em 2013 pela Versal Editores.

Os organizadores do livro Armando Almeida, Maria Beatriz Albernaz e Maurício Siqueira reuniram um considerável acervo de artigos, entrevistas e discursos dos Ministros da Cultura Gilberto Gil e Juca Ferreira. Um filtro inicial de análise da obra reside no registro do "estabelecimento de novos signos discursivos pela fala e pela escrita" em "um período de grande agitação na cultura brasileira". Em sentido complementar, a breve introdução escrita pelos organizadores destaca que as gestões de ambos os Ministros são reconhecidas como um momento em que a "palavra que trata do fazer cultural tornou-se, ela mesma, expressão da cultura", síntese que confere o título para o livro.

A envergadura do projeto editorial exigiu a pesquisa para a identificação e localização de um conjunto de textos dispersos com a passagem do tempo, escritos com objetivos e fins diversos para instituições do governo, imprensa, universidades, redes de movimentos sociais, fóruns, conferências, etc. A busca de unidade ao material esparso encontrado pelos organizadores resultou na escolha metodológica de classificação dos escritos "por autor, modalidade e ordem cronológica" ao longo do livro.

O cuidadoso projeto gráfico, diagramação e revisão da obra proporcionam o acesso ao iniciante e a fonte para "estudiosos e agentes da cultura" sobre diferentes temas. O leitor encontrará ensaios sobre as políticas culturais desenvolvidas no período, passando pela efetivação de direitos humanos, direitos autorais e conexos, cultura digital e novas tecnologias, democracia deliberativa e conferências da cultura, o Plano Nacional da Cultura, desenvolvimento sustentável, entre outros. É justamente a exposição dos fundamentos dessa ampla gama de assuntos e sua relevância na compreensão dos novos arranjos institucionais no campo das políticas culturais que constituem o diferencial da publicação. 
A natureza da obra não reside somente no registro da memória ou da narrativa institucional relacionada ao Ministério da Cultura entre 2003 e 2010. Uma espécie de nostalgia do período, para utilizar uma expressão evocada por Juca Ferreira em uma mesa redonda sobre o livro realizada na cidade de Belo Horizonte. Em sua essência, a obra trata da ampliação dos sentidos da política, o processo de interpretação e valorização positiva da diversidade cultural, práticas de cidadania ativa e a aproximação com uma perspectiva socioambiental.

Há uma corrente crítica à gestão de ambos no Ministério da Cultura e que questiona a morosidade no aperfeiçoamento das regras de setores como o de audiovisual, fomento e financiamento de projetos culturais, flexibilização de direitos autorais e a emergência de direitos conexos, com as novas de forma de licenciamento e gestão de conteúdos. Há, também, dissonâncias e desentendimentos de membros das equipes que compuseram as gestões e expuseram suas opiniões na esfera pública. Um terceiro perfil crítico questiona a autoria de determinados escritos, os quais teriam a contribuição maior ou menor de interlocutores próximos.

Não obstante, a leitura do livro permite concluir que houve um esforço do Ministério da Cultura nas gestões de Gilberto Gil e Juca Ferreira em duas direções complementares, porém com dinâmicas temporais próprias e não sincrônicas: a) consolidar um arcabouço conceitual e instaurar novas práticas com programas governamentais tais como Cultura Viva e os Pontos de Cultura, além da incorporação transversal das noções de cultura digital, territórios e redes culturais, etc.; b) instaurar novas rotinas administrativas voltadas à formação de consensos e processos decisórios legitimados pela via da deliberação pública.

Gilberto Gil privilegiou uma comunicação diferenciada com a sociedade civil, em que além de aproximar a cultura com o meio ambiente, a revolução digital, a cidadania e o desenvolvimento sustentável, destacou a potência criativa de um pensamento imagético. Por exemplo, no ensaio Nossas Bacias Culturais, publicado originalmente no jornal Correio Braziliense, em 13 de dezembro de 2005, ele articula a imagem da "teia" para compor uma cartografia imagética do Sistema Nacional de Cultura que enfatiza a noção de "bacia cultural", diluindo a força política das regiões geopolíticas da federação (Almeida, 2013: 22). 
Os sentidos da noção de cultura são expostos por Gilberto Gil no conjunto de seus pronunciamentos iniciais. Nos discursos, três dimensões representativas são programaticamente articuladas e interligadas pela gestão, ao considerar a cultura como "usina de símbolos", como "direito e cidadania" e como "economia".

Essas dimensões representativas da cultura foram materializadas em políticas públicas por meio de ações como os Pontos de Cultura, qualificados por Gilberto Gil como "intervenções agudas nas profundezes do Brasil, para despertar, estimular e projetar o que há de singular e mais positivo nas comunidades, nas periferias, nos quilombos, nas aldeias: a cultura local" (Almeida, 2013: 328).

A possibilidade de amplificar manifestações e expressões culturais de diferentes comunidades e coletividades brasileiras a partir de um conjunto articulado de políticas, respeitar o caráter plural dessas experiências e ao mesmo tempo materializar o acesso e a comunicação à esfera pública dos debates sobre educação, saúde, direitos, cidadania, tecnologias sociais, organização social, etc. são elementos para compreender a complexidade das propostas gestadas e executadas pelo Ministério da Cultura a partir de 2003.

O entrelaçamento entre cultura e cidadania ativa nos Pontos de Cultura constitui o fio condutor do vídeo documentário O Rosto no Espelho (2009), com roteiro e direção de Renato Tapajós. Elaborado originalmente como uma encomenda de agentes do Ministério da Cultura, tal como o livro Cultura pela palavra o filme transpassa uma linha argumentativa de divulgação de ações do poder público e permite ao interlocutor o reconhecimento e o encontro com alteridades muito diversas entre si. Em sua narrativa fílmica, Renato Tapajós destaca ao registrar o cotidiano de diversos Pontos de Cultura a emergência de um novo sujeito de direitos culturais, perpassando diferentes gerações e reposicionando o potencial de organização social e de criação de bens culturais.

A Constituição Federal de 1988 assegurou aos direitos culturais o estatuto de direitos fundamentais das pessoas. E Gilberto Gil destaca que "o reconhecimento global de que cada sociedade, grupo social e indivíduo têm um patrimônio cultural singular" permite refletir "um sistema de valores e um modo de viver próprio, a partir do qual se dá a sua identidade" (Almeida, 2013: 335). Paradoxalmente, o processo de patrimonialização e a gestão pública inscreve esses bens culturais entre os limiares do legado para as gerações futuras e as "coisas" a serem administradas, inclusive nas relações com o mercado da indústria cultural. Como sair deste paradoxo? 
Talvez não haja saídas. No ensaio Hegemonia e diversidade cultural, publicado inicialmente no jornal Le Monde Diplomatique Brasil, Gilberto Gil nos lembra que a "palavra cultura tornou-se um sinônimo hoje de tudo o que buscamos como aspiração mais elevada. Ao escolher esse caminho, temos que tomar a precaução de não esvaziar o sentido pleno da experiência cultural." E desse modo, não bastaria "somente associarmos cultura a ideias positivas classicamente assentadas entre nós, como a noção de lugar, de modos de viver, modos de ver e olhar", pois "não se deve suprimir a complexidade e historicidade da ideia de cultura em nossos séculos e em nossos dias" (Almeida, 2013: 24).

O "tempo único e a linearidade do velho mundo" são desalojados e "no plano dos estudos - principalmente na antropologia - e nas políticas de identidade, no plano das lutas coloniais e pós-coloniais das multidões, essas forças intelectuais e sociais deslocaram esse tempo egoísta do homem alojado no centro do universo e fraturaram o centro geopolítico do mundo. Revelaram um planeta multicêntrico, com muitas narrativas e imagens de si próprio" (Almeida, 2013: 25).

Enfim, a constituição do bem comum está sempre sendo forjada e sua interpretação não pode ser anacrônica. O tempo dos avanços sociais e das transformações almejadas possui uma dinâmica própria. A interação entre liberdade e responsabilidade alçada à condição de princípio constituinte da vida pública por Alfredo Bosi poderia muito bem constituir uma síntese da complexa relação entre cultura e poder público traçada pelo livro A cultura pela palavra. O que diria Mário de Andrade se estivesse vivo?

\section{Referências}

ALMEIDA, Armando; et alii. (Org.) Cultura pela palavra: coletânea de artigos, entrevistas e discursos dos ministros da Cultura 2003-2010, Gilberto Gil e Juca Ferreira. Rio de Janeiro, Versal, 2013.

BOSI, Alfredo. Dialética da colonização. São Paulo: Companhia das Letras, 1992. . Interação virtuosa. Revista Carta Capital, n. 627, 22 dez. 2010. Ler é resistir. Entrevista: Alfredo Bosi. Revista Época, n. 256, 14 abr. 2003.

LIMA BARRETO, Afonso Henriques de. Lima Barreto: toda crônica. Rio de Janeiro: Agir, 2004, vol. II (1919-1922).

O ROSTO no espelho. Direção: Renato Tapajós, 2009. (57 min.) Disponível em: https://www.youtube.com/watch?v=w09p_HIOcMs. Acesso em: 7 dez. 2016.

Recebido em: 30/01/2017. Aprovado em: 13/04/2017. 